\title{
AS DUAS FACES DA MESMA MOEDA: ULTRANEOCONSERVADORISMO E ULTRANEOLIBERALISMO NO BRASIL DA ATUALIDADE*
}

\author{
Maria Elizabeth S. Borges \\ Maurílio Castro de Matos
}

Este capítulo pretende refletir sobre a conjuntura brasileira de ataque aos direitos da classe trabalhadora e à diversidade humana, indicando como hipótese que se encontra em curso no país a implementação de um projeto ultraneoliberal, que tem como sua contraface um projeto ultraneoconservador.

Busca refletir sobre a necessidade de se identificar nitidamente que projeto é esse e qual o seu impacto para a classe trabalhadora e para o Serviço Social, ao dialogar com o rebatimento no trabalho de assistentes sociais, uma vez que esses/as profissionais lidam diretamente com a população que mais vem sendo atingida no ataque aos seus direitos, tanto pela redução das políticas sociais, como pelo controle das suas formas de agir e pensar.

O Serviço Social brasileiro construiu um projeto de profissão afinado com a afirmação dos direitos da classe trabalhadora e seus posicionamentos acabam também sendo questionados. Assim, a reflexão crítica que se pretende realizar, busca desnudar a realidade, problematizando, especialmente, o discurso de ataque à diversidade humana, tratado por alguns analistas como "cortina de fumaça".

Partimos de uma breve análise da conjuntura, tomando os marcos do início do segundo ano do governo Bolsonaro e seu impacto para a classe trabalhadora. Uma das fontes de pesquisa sobre os posicionamentos da categoria profissional foi o documento do conjunto CFESS-CRESS, denominado "bandeiras de luta", que reúne posicionamentos tirados no último Encontro Nacional CFESS-CRESS (gestões 2017-2020), que representam concepções de representantes de base e da direção de Conselhos Regionais de Serviço Social do país (CFESS, 2020). Dividimos o artigo em três partes, partindo da análise de conjuntura, da exposição da hipótese de trabalho e levantando algumas questões relacionadas ao Serviço Social na atualidade.

*DOI - 10.29388/978-65-86678-20-8-0-f.71-88 


\section{Que país é esse? A pergunta que persiste}

A pergunta, formulada pelo poeta Renato Russo e cantor do grupo de Rock brasileiro Legião Urbana, em 1987, parece-nos ter atualidade no Brasil de hoje, pois continuamos perplexos diante da expressão pública que busca legitimar uma moralidade conservadora e de novas incertezas no plano econômicosocial e político. Especialmente nas duas últimas décadas, o vertiginoso aumento das denúncias de violência - denúncias estas que vieram à tona devido a redemocratização e a organização combativa de diversos movimentos sociais que atingem diversos segmentos sociais, especialmente quem luta pelo direito à terra e quem ousa viver fora do padrão dominante, como é o caso da população LGBTI, ou daqueles que trazem em suas vidas a marca de nossa formação social, como é o caso das mulheres e homens negros vítimas do racismo estrutural no país. Os fatos denunciam que a democracia racial no Brasil é mais uma mistificação.

O momento atual faz expressar um grau novo de discriminação, marcado pela explicitação e pela naturalização de preconceitos, que têm a sua origem nos juízos provisórios, necessários para o agir humano na cotidianidade. Segundo Heller (1992), quando a ciência, ou uma experiência cuidadosa analisada, refuta esse juízo provisório, mas esse se mantém como referência para os sujeitos que o recorrem, aí se transformam em preconceitos. Assim, compreende-se que a existência de preconceitos, não é um fenômeno novo, a novidade é ser, na sua expressão pública, a busca em legitimar o ódio de classe, raça, etnia, orientação sexual, identidade de gênero e etc., como formas de desvalores sustentados por representantes do executivo e de parte da sociedade civil. O que compreendemos como desvalor, sustenta-se em Heller (1992, p. 4-5), quando afirma:

[...] valor é tudo aquilo que faz parte do ser genérico do homem e contribui, direta ou mediatamente, para a explicação desse ser genérico. [...] e pode-se considerar desvalor tudo o que direta ou indiretamente rebaixe ou inverta o nível alcançado no desenvolvimento de uma determinada componente essencial. O valor, portanto, é uma categoria ontológico-social [...] (Grifos originais)

A conjuntura se explica na relação com a estrutura e, pelo desenrolar dos acontecimentos, desde a interrupção do governo de Rousseff (2016), estão explícitos os interesses da direita, que era facilitar o caminho das políticas neoliberais no plano econômico. O golpe parlamentar-midiático, que permitiu a as- 
censão de Temer ao poder, abriu a trilha para a aceleração da concepção neoliberal nas políticas sociais e na condução do Estado, que nada mais é do que carrear recursos para o sistema financeiro-especulativo, com congelamento de recursos e inversão de prioridades.

O governo Temer explicitou que a questão social vem sendo enfrentada como questão de polícia, com a militarização de favelas, incentivo a medidas de força em nome da ordem, guerras declaradas ao tráfico de drogas, homicídios e outras tantas demonstrações da intervenção armada e da herança da doutrina de segurança militar, com desenvolvimento da indústria armamentista (ela mesma, uma fonte de lucro). Foi um governo ilegítimo, que pavimentou as bases para o que veio a seguir, inclusive com a aprovação da EC95/2016, que congelou os investimentos em saúde e educação por vinte anos.

Pelo processo eleitoral em 2018, o rumo político levou à opção extremada e totalitária, com a chegada de Bolsonaro ao poder, com suas propostas muito mais aviltantes e já tendo conseguido emplacar as reformas previdenciária e trabalhista em seu primeiro ano de governo. A eleição de Bolsonaro evidenciou este potencial de forças em presença na sociedade e de manifestações neofascistas ${ }^{1}$, com articulação de milícias, assassinatos políticos, prisões arbitrárias, discursos de ódio, ações antidemocráticas, demonstração de autoritarismo na relação com o conhecimento, com a cultura e com as artes e no plano econômico, a consolidação do ultraneoliberalismo.

Essas ideias, entretanto, não nasceram de Bolsonaro, já germinavam na sociedade, ele e seus aliados souberam capitalizá-las e transformar em poder, unindo-se às forças reacionárias, de matriz fundamentalista; foi buscar no recôndito da sociedade, de raiz escravocrata, racista e elitista. E aqui nos apoiamos em Gramsci (2016, p. 83), quando diz: “as ideias e opiniões não 'nascem’ espontaneamente no cérebro de cada indivíduo: tiveram um centro de formação, irradiação, difusão e persuasão [...]"

Em seu segundo ano de governo, consolida-se a ameaça no campo da formação acadêmica, com a perseguição ideológica às universidades públicas, manifestas nos cortes e contingenciamento de recursos, suspensão de programas e de bolsas para iniciação científica, para a pesquisa acadêmica, dificuldades para manutenção da política de cotas e de permanência na Universidade, um evidente enfrentamento à democratização desta instituição secular, reforçando o modelo de universidade privatista e elitista. A perseguição aos movimentos de defesa das pautas progressistas; LGBTQIA+, quilombolas, mulheres, indígenas,

${ }^{1}$ Sobre o fascismo e suas expressões na atualidade, realizaremos adiante algumas considerações. 
meio ambiente. A perseguição à chamada "ideologia de gênero" e projeto como "escola sem partido". Na saúde, o sucateamento do SUS, com recursos e incentivos direcionados à iniciativa privada. $\mathrm{Na}$ assistência social, recrudescimento dos critérios de acesso ao Bolsa Família e ao Benefício de Prestação Continuada (BPC) e mais os estragos na Previdência social, com novas regras para os cálculos atuariais para aposentadorias e acesso aos benefícios, como pensões.

Em meio a pandemia da COVID-19, falas do presidente contrárias ao distanciamento social da população, em direção oposta ao conhecimento científico, expressando explicitamente a preocupação com os lucros dos empresários. A busca de enfrentamento à pandemia demonstrou as aviltantes condições de trabalho, afora a tentativa de redução de salários, censuras e outras barbaridades. E por fim, sem esgotar os exemplos, a constatação dos ataques à democracia, com o governo perseguindo ideologicamente a imprensa, buscando substituí-la por "Fake News" em redes sociais, que é a forma do executivo se comunicar com a sociedade.

O que acontece no Brasil não é isolado, pois, o sistema do capital pressupõe a crise, ela não é um defeito do capitalismo, mas é-lhe inerente, até necessária ao equilíbrio no desequilíbrio da dinâmica do capital e muitas vezes, é até provocada. Os estudos sobre as crises cíclicas já mostraram a origem e o significado das crises estruturais do capitalismo, a exemplo das obras de Mandel, Chesnais, Mészáros, Harvey, dentre outros. O que diferencia a crise atual das demais é sua persistência no tempo, sem que o capital tenha ativado seu pleno poder de recuperação do padrão de acumulação, mas, ao contrário, vai demonstrando a saturação do seu projeto de desenvolvimento econômico; vejamos por exemplo, a tendência da queda da taxa de lucro das empresas, o elevado percentual de desemprego e a crise ambiental. Os problemas e contradições desse sistema só tem se ampliado, ainda que contidos ideologicamente.

Algumas características são peculiares ao momento atual do capitalismo em sua crise estrutural de longa duração, como o aumento do poder do capital sobre o trabalho, a reestruturação produtiva com expulsão de força de trabalho, com consequente aumento do desemprego e da exploração; do ponto de vista dos interesses do capital, as medidas de contenção da crise têm sido por redução e congelamento de salários, demissões, privatizações, elevação de impostos, flexibilização das regulações do mercado de trabalho, cortes de gastos sociais, aumento da idade para aposentadoria, reformas tributária, trabalhista, ou seja, tendências regressivas. Em síntese, o governo atual só está realizando uma agenda programada e em consonância com os interesses do capital financeiro.

O que acontece é que, no Brasil, mas não apenas por aqui, se aliou à 
agenda econômico-financeira, um aprofundamento do neoconservadorismo. O governo tem se manifestado pelo culto à violência policial e ideologia repressiva (rebaixamento da idade penal, armamentismo, extensão de penalidades) e também pelas intolerâncias às "minorias" sexuais, com fortes apelos religiosos (contra legalizações: aborto, drogas/produtos psicoativos, uniões homoafetivas). Para Gramsci (2016, p. 187), "as crises consistem justamente no fato de que o velho morre e o novo ainda não pode nascer: neste interregno, verificamse os fenômenos patológicos variados". Diríamos que estamos vivendo nosso momento de patologia.

O que perguntamos é sobre as características fascistas no bloco do poder executivo, localizando o fascismo na história. Este surge na Europa nos anos 1920-30, em vários países, existindo movimentos, ou mesmo governos fascistas e por isso foi tema do III Pleno ampliado do Comitê Executivo da Internacional Comunista, em junho de 1923, quando Clara Zetkin ficou responsável por realizar um informe e uma resolução sobre o fascismo.

Zetkin (2019) realizou uma crítica, ao dizer que o partido comunista ignorou o poderio ideológico e político do fascismo, ao entendê-lo somente como um movimento militar, enquanto que na sua compreensão se tratava de um fenômeno internacional, funcional ao capitalismo, na medida em que tinha como alvo a classe trabalhadora. Daí, a importância da união entre os proletariados no seu combate, na constituição de uma frente única².

Taber e Riddell (2019: 20, 21) apontam as seguintes características do fascismo: seu surgimento está imbricado com a crise do capitalismo e seu ataque à classe trabalhadora; emerge devido à incapacidade do proletariado em enfrentar essa crise e tomar o poder; tem um caráter de massa com especial apelo à pequena burguesia ${ }^{3}$; a sua ideologia eleva a nação acima dos interesses e contradições das classes; em defesa do nacionalismo, recorre às forças armadas

\footnotetext{
2 Tratava-se de uma reflexão coletiva. Trotsky estava presente nesse pleno e como é de conhecimento público, em seu exílio, defendeu vigorosamente em vários textos a frente única. Gramsci, também estava presente e foi, de acordo com Trotsky o primeiro integrante do recém-nascido partido comunista Italiano a atentar para as reais características do fascismo, a partir da crítica a Mussolini. O autor sardenho continuou seus escritos de combate ao fascismo na prisão, marca da sua obra.

${ }^{3}$ Como aponta Calil: "Uma das características fundamentais do fascismo, em suas distintas experiências históricas, é o fato de que, embora quando no poder tenha expressado os interesses do grande capital (como as políticas concretas dos regimes fascistas comprovam fartamente), ele não se constitui inicialmente como organização impulsionada pela grande burguesia. Ao contrário, sua ascensão foi impulsionada fundamentalmente por setores intermediários, muito especialmente a pequena burguesia" (2019:53).
} 
com uso da violência, a ideologia do racismo é central e recebe apoio das classes dominantes, que veem no fascismo a possibilidade de frear a organização da classe trabalhadora.

De acordo com Bottomore (2001, p. 147-148) existem, em geral, três elementos presentes na conjuntura de emergência do fascismo: o "capitalismo monopolista", "uma aguda crise econômica" e "posição ameaçada de grandes segmentos da classe média".

A partir de 1924, com a morte de Lenin, houve uma mudança de postura da Internacional Comunista em relação ao fascismo, ao trazer a tática de tão importante quanto o combate ao fascismo era também o combate à socialdemocracia e com isso, foi superada a resolução que defendia uma frente única. Os escritos de Trotsky, no seu exílio contra Stálin, criticavam também contundentemente esse posicionamento. Trotsky tem várias passagens, onde destaca a confusão desse, suposto, duplo combate tirado à época pela internacional comunista. Destacamos este:

A social-democracia, que hoje é o representante principal do regime parlamentar burguês, apoia-se nos operários. O fascismo porém, apoia-se na pequena burguesia. A social-democracia não pode ter influência sem as organizações operarias de massas. O fascismo, porém, não pode consolidar o seu poder de outra forma, senão destruindo as organizações operárias. A arena principal da social-democracia é o parlamento. O sistema do fascismo é baseado na destruição do parlamentarismo. Para a burguesia monopolista, o regime parlamentar e o regime fascista não representam senão diferentes instrumentos de sua dominação: recorre a um ou a outro, segundo as condições históricas. Mas para a social-democracia, como para o fascismo, a escolha de um ou outro instrumento tem uma importância própria; mais ainda, é para eles uma questão de vida ou de morte política (Trotsky, 2018, p. 87).

Parece evidente que não existe uma única forma de manifestação de fascismo, variando em cada país, conforme já atentavam Zetkin (2019) e Trotsky (2018), por exemplo. De tal maneira, não se pode transpor o fascismo histórico para o da atualidade, que se manifesta conforme as particularidades em cada região.

O discurso do presidente Bolsonaro, como pretexto de combate à esquerda e em defesa de um projeto de ultradireita, expressa o ódio à diversidade humana, a ênfase da misoginia, a defesa do armamento para o enfrentamento das expressões da questão social, dentre outras. Essas manifestações presidenci- 
ais, trazidas aqui como exemplos, uma vez que não esgotam os conteúdos de seus discursos, fez emergir a preocupação com a possível instalação do fascismo ao modo tupiniquim.

Os artigos coligidos em Cislaghi e Demier (2019), buscam analisar se seria o governo Bolsonaro fascista e avaliam que não há dúvidas de que existem elementos fascistas, mas que não se trata, ainda, de um Estado fascista. Tal conclusão, em nada pode ser vista como um alento, na medida em que a experiência histórica mostra que o fascismo como modo de governo se instalou processualmente, em geral após eleições democráticas, embora Löwy (2012) considere que no Brasil ainda não há um partido de extrema direita que lhe dê sustentação. Entretanto, cabe problematizar sobre as particularidades do frágil sistema partidário brasileiro - a exemplo do próprio presidente que já desde o seu primeiro ano de mandato, encontra-se sem partido, mas que não o vem impedindo de obter vitórias (não todas) nas suas pautas enviadas ao Congresso Nacional donde essa característica tanto pode ser potencializada a favor, ou seja, um empecilho ao seu projeto de cunho fascista. Conforme, abordamos não se trata de uma transposição. Existem, sim, traços alarmantes que confirmam se tratar de um governo com ideais e ações fascistas, mas que se materializam em outro momento histórico e em outra região, com histórias particulares, do planeta.

Se está correta a hipótese de que estamos vivendo um governo com elementos fascistas e, lembrando, não significa dizer que o fascismo está instaurado como um governo, embora contenha elementos do que pode vir a ser, consideramos necessário refletir criticamente sobre o discurso acerca da "cortina de fumaça”, pois, se esta hipótese estiver correta, nada tem de acessório a crítica à diversidade humana e às pautas identitárias realizada pelo presidente da república e seus representantes governamentais.

\section{A “cortina de fumaça” como interesse político}

Em termos literais, "cortina de fumaça"significa uma nuvem espessa de fumaça produzida pelas chaminés dos navios de guerra, ou feita artificialmente com produtos químicos, cujo propósito é encobrir a visão dos oponentes para despistá-los, enganá-los. Por isso, costuma-se dizer que qualquer atitude que iluda, engane, amenize e/ou despiste as reais intenções ou motivos, há uma tentativa de jogar uma "cortina de fumaça".

A expressão tem sido utilizada por analistas políticos toda vez que o presidente Bolsonaro, ou seus ministros ventríloquos, se pronunciam sobre as 
pautas identitárias, distorcendo seus significados políticos e levando para um campo da moralidade, o que mobiliza reações na sociedade. Este movimento vem se dando simultaneamente à aprovação das pautas econômicas mais recrudescidas, com cortes e restrição de direitos. Segundo as análises, este mecanismo vem sendo utilizado para desviar o foco e minar a força da classe trabalhadora no enfrentamento para manter direitos conquistados.

O que queremos indicar como questão é que, a "cortina" não é apenas um detalhe para desviar a atenção, pois, também apontam para a eliminação de ações de políticas públicas de interesse de segmentos tradicionalmente invisibilizados. Acontece, que os pronunciamentos oficiais mobilizam o pensamento conservador, reafirmam um lugar de desimportância dessas pautas, paralisam o processo de discussão crítica e de construção de valores libertários; em nosso entendimento, a identidade de gênero, orientação sexual e cor/raça devem ser integrantes das lutas sociais da classe trabalhadora e são parte de um mesmo problema.

A classe trabalhadora, em qualquer de seus estratos, vive a crescente pauperização, ampliando o público atendido no âmbito das políticas assistenciais, usuários dos serviços profissionais em seus diversos espaços de trabalho. A nossa hipótese é que, este campo de debate não pode ser dissociado do plano econômico e não pode ser tomado apenas como "desvio de atenção". No nosso entendimento, o campo da esquerda não pode levar o argumento para o lugar da "piada governamental".

Do nosso ponto de vista, abandonar as lutas do direito à diversidade humana a seus "guetos" é reafirmar preconceitos e hierarquizações sociais e, portanto, um equívoco. Os ataques à diversidade devem ganhar a centralidade necessária no desvelamento da realidade, pois, não é outra coisa (a tal cortina), mas, ao contrário, são temas que integram o mesmo fenômeno. Por isto, a esquerda não pode reproduzir argumentos que sugiram que a estrutura se sobrepõe à superestrutura, como momentos diferenciados, quando Gramsci já demonstrou a superação dessa hierarquia. Como já demonstrado, a subjetividade é parte estruturante do ser e se forja nas relações sociais de classe, de raça/cor e de sexo.

Gramsci não pode ser esquecido na discussão sobre a superação dessa hierarquia, dado que seus estudos apontaram uma leitura crítica da concepção marxiana sobre o papel da estrutura nos processos de transformação social, na medida em que o século XX tem novos dados sobre o Estado e a sociedade civil. O estágio do capitalismo vivenciado pelo pensador e ativista político italiano evidencia que, "as superestruturas da sociedade civil são como o sistema de 
trincheiras na guerra moderna" (2016, p. 73), conclusão a que chega por se dedicar à compreensão da cultura, do Estado, da hegemonia e do papel dos intelectuais orgânicos, atualizando o papel das instituições representativas das classes dirigentes.

Além da crítica que realizamos a uma tendência de parte da esquerda de hierarquizar direitos e logo lutas, entendemos de que não se pode tratar apenas como se fosse uma "cortina de fumaça", se compreendermos que estamos lutando contra um governo com características fascistas, onde nenhum dos seus gestos pode ser considerado aleatório e desinteressado.

Ainda que não possamos transpor abruptamente o fascismo histórico para a atualidade, podemos aprender com a história de que o fascismo se sustentou no racismo, com construção, inclusive, normativo-jurídicas e da medicina. O racismo fascista, não foi "apenas" um terrível preconceito identitário, mas possibilitou, com base na "lei" e na "ciência" a exclusão de amplos segmentos aos seus direitos e, com isso, o redirecionamento de recursos - seja pelo saque dos que tinham alguma renda ou pelo descompromisso do Estado com a reprodução desses sujeitos - para alavancar o capital.

A tal "cortina de fumaça" só evidencia a reprodução de preconceitos arraigados em nossa sociabilidade, a julgar pelos posicionamentos do governo quanto a atitudes que traduzem a LGBTIfobia, a fala da ministra que representa as mulheres, de que meninas vestem rosa e meninos azul, de que meninas indígenas são mais estupradas porque não usam calcinhas, a ênfase nas comunidades terapêuticas para tratamento da saúde mental, de que o governo não deve ser responsável por tratamento para quem se infectou por sua responsabilidade por alguma Infecção Sexualmente Transmissível - IST/AIDS, dentre outras barbaridades. Estes ditos não conformam uma questão acessória, têm no seu horizonte o redirecionamento de "gastos" do Estado para com certos "segmentos" da população, logo não são uma cortina e sim, o fogo que alimenta o conservadorismo na sociedade brasileira e evocando o dito popular, "onde há fumaça, há fogo"!

Para Barroco (2015), o conservadorismo é a reprodução ideológica de um conjunto de determinações estruturais e conjunturais. Não estaria dissociado das ideias formuladas no campo da direita e/ou da ultradireita. De modo geral, o que caracteriza o pensamento conservador é o esvaziamento do conteúdo histórico, a defesa de desfiliação teórica e a valorização de preconceitos em nome da tradição e das evidências empíricas e a negação da totalidade e do "totalitarismo" (como se referem às experiências socialistas). 
O conservadorismo reinante, como disse o jurista Pedro Serrano ${ }^{4}$ em palestra local, nos leva a viver o lado sombrio de nossa sociedade, nossas mais profundas contradições, onde parte da elite não esconde seus preconceitos e ódio, não está interessada em integrar a nação e tem medo de perder o controle histórico do poder; segundo ele, o inimigo é étnico e tem classe e na dimensão do afeto isto é incontornável. Seguindo seu raciocínio, isto demonstrou o limite da estratégia de conciliação de classe num país como o Brasil, de extrema desigualdade social e cultural.

Enfim, as ideias contemporâneas respondem às necessidades deste tempo histórico, de barbárie, fragmentações, esgarçamento do tecido social e de retomada de práticas conservadoras e irracionalistas, no interior das instituições. O pensamento conservador adquiriu contornos específicos no contexto da divisão internacional do trabalho e sua recusa é ao pós-capitalismo. Cabe-nos perguntar, como assistentes sociais enfrentam o confronto com esses projetos em evidência nas instituições do trabalho profissional.

\section{O Serviço Social e o confronto com o projeto ultraneoliberal e ultraneoconservador}

Do que já expusemos, a síntese que fazemos é que a roda da História gira, e agora, vivemos um novo ciclo do padrão de acumulação capitalista e de acomodação do Estado autocrático burguês, nos termos de Netto (1992). O que caracteriza este novo ciclo da ordem do capital, em grandes linhas, é a hegemonia e o modelo do capitalismo financeiro.

Especialmente no Brasil, neste ciclo de liberalismo ultra-acirrado (ultraneoliberalismo), as práticas vêm sendo reorientadas por um conservadorismo de direita, também exacerbado (que denominamos ultraneoconservadorismo), uma vez que recorre ao fascismo. Seria uma nova etapa do projeto neoliberal, com a conjugação de um projeto ultraconservador, que busca naturalizar desvalores, para legitimar o neofascismo e que vai repercutir - diretamente - nos es tratos mais baixos da classe trabalhadora, uma vez que estes são vistos como mais dispensáveis. A nossa principal preocupação neste debate é que relação isso estabelece com a profissão e quais nossas chances e tarefas para o seu enfrentamento. Este é um tema para o debate que se inicia entre nós e que nos convida a novas e urgentes investigações.

4 Professor de Direito Constitucional da PUC-SP e autor do livro: Autoritarismo e golpes na América Latina (Almada) 
Na perspectiva de análise que assumimos aqui, nenhuma forma social está dissociada de uma totalidade e de sua materialidade. Os fenômenos dessa totalidade aqui recortados, só fazem sentido se estudados em seus nexos estruturais e conjunturais. O conservadorismo será tomado como um singular, abstrato, se não configurado em seus laços de concreção: a sociedade que lhe dá guarida e chão histórico; a sociabilidade burguesa, como a totalidade complexa e situado na particularidade da sociedade brasileira.

O que demarcamos é a apreensão da realidade nos marcos de referências conservadoras, por parte do governo e seus representantes, repercutindo nas políticas sociais e culturais. Muitos são os fatos cotidianos que nos instigam a problematizar o conservadorismo da contemporaneidade: ainda não está traçado um plano das esquerdas, com consequente avanço político das forças de direita; o conservadorismo está nas ruas, no parlamento, na mídia, no governo, na sociedade e ganhou terreno. Manifesta-se nas desregulamentações de direitos, na naturalização de maus tratos contra mulheres, LGBTQIA+, populações de rua, violências domésticas e públicas.

Algumas referências e argumentações que nos permitem situar o conservadorismo em tempo de "capital fetiche" (Iamamoto, 2008), quando está em curso a crise estrutural no plano econômico e uma crise moral no plano cultural e político, com a degradação do trabalho e da vida social; manifestação de violências objetivas e subjetivas; e comportamentos desumanizantes. Algumas perguntas são: como entra, na atualidade, o conservadorismo no universo do trabalho profissional? No avanço de um projeto neofascista no Brasil, como se alterarão as requisições para a profissão?

O Serviço Social, na sua origem, teve uma forte influência do pensamento conservador cristão, com motivações morais para justificar a profissão como vocação. Nos primórdios da regulamentação havia a exigência da comprovação de idoneidade moral para ingressar nos cursos de Serviço Social, por exemplo, evidenciando um posicionamento acrítico. Em plena década de 1960, a $\mathrm{ABESS}^{5}$ publicou um livro de origem europeia, intitulado "código moral do Serviço Social”, onde afirma que o assistente social deverá sempre defender a "noção exata de família" contra o divórcio, o aborto, o concubinato, o amor livre e a infidelidade (Barroco, 2001, p. 124), revelando a moralidade dominante.

A profissão surge como um dos mecanismos que o capitalismo dispõe para minimizar os efeitos da questão social, mas ao compreender o caráter de classe desta demanda, e as contradições que envolvem a existência da profissão

${ }^{5}$ Entidade criada em 1946, atualmente denominada Associação Brasileira de Ensino e Pesquisa em Serviço Social - ABEPSS. 
nesta sociabilidade, parte da categoria se rebelou contra essa origem, encontrando outro caminho para a legitimidade social do Serviço Social. Embora não se possa mudar o lugar e o significado da atividade profissional no processo de acumulação da riqueza e exploração do trabalho, fonte da pobreza e das desigualdades na sociedade capitalista, pode-se assumir um lugar na luta pela superação desta mesma ordem que originou a profissão.

O rompimento com o pensamento conservador e positivista, no nível do debate e do posicionamento ético-político das entidades do Serviço Social, começou no final dos anos 1970, donde é paradigmático o Congresso da Virada de 1979. O projeto profissional que parte expressiva da categoria dos assistentes sociais vem construindo desde então, denominado projeto ético-político do serviço social, se pauta em uma recusa ao histórico conservadorismo da profissão e aponta para a construção de um exercício profissional comprometido com a justiça social e a liberdade, valores centrais do código de ética, promulgado em 1993.

Seria ingênuo imaginar que, após a emersão em fins dos anos 1970 e afirmação do projeto ético-político do Serviço Social, não existam respostas favoráveis, por parte de assistentes sociais, de requisições conservadoras, ou até mesmo a defesa dessas requisições. Afinal, o Serviço Social, como toda profissão, tem um heterogêneo corpo de agentes profissionais, com diferentes inserções de classe e de pertencimento social. Na batalha das ideias, (Coutinho, 1992) construiu-se uma hegemonia do pensamento crítico ao conservadorismo, permitindo aos profissionais sustentarem a concepção hegemônica de um projeto ético-político-profissional, ao longo das quatro últimas décadas. Este posicionamento é a referência da regulamentação da profissão e do trabalho profissional, como o código de ética, a lei de regulamentação da profissão, as diretrizes curriculares da ABEPSS e resoluções, subsídios e pareceres do Conjunto CFESS-CRESS.

O Serviço Social responde a demandas mediadas por instituições de um modelo estatal de enfrentamento à questão social, consoante ao padrão atual do capitalismo. A forma estatal e a forma capital estão plenamente ajustadas. Tomamos que o modo como o profissional vincula-se às instituições que lhes demandam serviços responde às necessidades sociais deste contexto específico; a nossa hipótese é que, na forma de enfrentamento da questão social na contemporaneidade, o Serviço Social está tensionado por um universo conservador, o que se constitui num grande desafio para a hegemonia do projeto éticopolítico-profissional. Na passagem do novo coronavírus em nosso país, assistentes sociais estão sendo pressionadas a assumir tarefas que não são próprias 
das suas atribuições, sofrendo assédios por parte de seus empregadores e se defrontando com as mais precárias condições de trabalho, bem como lidando com as dificuldades de contratos temporários, numa evidente ameaça à autonomia profissional.

Requisições conservadoras fazem parte historicamente do trabalho de assistentes sociais. Afinal, uma profissão que se funda no trato das expressões da questão social, recebe requisições diversas, sobretudo do empregador, para a individualização dos "problemas" apresentados pelos usuários, dificultando a compreensão dos problemas como expressão da desigualdade inerente à lógica e dinâmica capitalista. Responder requisições conservadoras, concordando com as mesmas, faz parte de uma determinada concepção ético-política de profissão e ao mesmo tempo, é objeto de negação de uma concepção crítica, que buscou superar esse conformismo que fez parte, explicitamente, da profissão por um largo tempo.

É nesse contexto que devemos nos indagar sobre as formas de enfrentamento dessa realidade. O imperativo ético, diante da realidade brutal de violências e violações de direitos, é negar a naturalização dos desvalores postos na ordem do dia. Este imperativo também tem sustentação jurídico normativa, de duas ordens. A primeira, refere-se às normatizações da profissão e a segunda, o marco das legislações sociais. Em ambas, pelo menos até o momento, está a negação dos desvalores governamentais exemplificados no decorrer deste artigo, se constituindo em infrações ética e legal, portanto, são instrumentos de trabalho no cotidiano da intervenção profissional.

Sem desconhecer as condições objetivas do trabalho, mas buscando uma responsabilidade coletiva, na construção de estratégias profissionais e cidadãs, que digam não ao ultraneoliberalismo e ao ultraneoconservadorismo, as questões que levantamos são direcionadas ao amplo campo de pesquisas sobre a profissão e seus desafios na atualidade, considerando a nova onda conservadora e a batalha das ideias.

\section{Considerações finais}

A ordem capitalista nos impõe desafios de diferentes ordens e a profissão tem que dar um novo salto, sob risco de sucumbir nas atualizações do conservadorismo e cair num pragmatismo cínico. Se a profissão é histórica, assim os são os seus dilemas e as suas respostas, portanto. No plano da formação é preciso tomá-la de forma continuada, pois, é preciso desenvolver instrumentos de análise da realidade social e dos fenômenos aparentes no universo do traba- 
lho profissional; precisa ser de qualidade, de excelência ético-política, teóricametodológica e técnica-instrumental, devendo por isso praticar a criatividade e inteligência. O que implica enfrentar e superar o pragmatismo das instituições e suas requisições pautadas em moralismo e preconceitos.

Como em Gramsci, o "pessimismo da inteligência" deve estar a serviço do "otimismo da vontade" e por isso, inspirados em Barroco (2001), podemos e devemos nos propor a enfraquecer a permanência do conservadorismo, ao denunciar sua ingerência, recusar apelos moralistas, expor a faceta cruel do capitalismo, denunciando atos de barbárie, alargar as bases democráticas de nossa atuação profissional e não acatar a moralização das expressões da questão social. Estaremos atentas à dinâmica societária, com capacidade de fazermos leituras críticas e de abertura à reposição cotidiana das lutas dos sujeitos pela expansão e cumprimento de direitos, solidárias a grupos minoritários em suas expressões de apelo à dignidade e condição de humanidade, reconhecendo as estratégias de resistência e de luta contra as durezas da vida cotidiana da classe trabalhadora e seus estratos mais precarizados atendidos nos serviços públicos.

Esta tarefa de forte conteúdo ético-político, que deve ser encarada coletivamente, a partir das condições objetivas e com recursos aos acúmulos existentes dentro e fora da profissão, inclui novos estudos e problematizações sobre o pensamento neoconservador de corte fascista na atualidade. Segundo Iamamoto (2008), Guerra (2013) e outras, ainda não fizemos um estudo crítico, de aprofundamento das bases teóricas e epistemológicas sobre a presença do pensamento conservador na profissão. É sabido que, só uma parcela de profissionais buscou superar as influências conservadoras, submetendo-se ao crivo da crítica e assumindo uma outra postura e valores profissionais, mas não quer dizer que houve a superação total do conservadorismo na profissão, haja vista as suas reatualizações, expressas, inclusive, nas respostas pragmáticas, fragmentadas e massificadoras.

É próprio de humanos realizar escolhas, determinadas historicamente, cuja noção de liberdade introduz a ideia de "possibilidade objetiva" (Chaui, 1997, p. 362). Define Chauí que "a liberdade é a capacidade para perceber as possibilidades e o poder para realizar aquelas ações que mudam o curso das coisas, dando-lhe outro sentido". Na filosofia mora nossa inspiração para decifrar os fenômenos que interferem, ou mesmo, constituem nossos campos de atuação profissional e das questões que dizem respeito aos usuários dos serviços; está aí um campo fértil de investigação sobre a influência (ou presença) do conservadorismo na profissão e qual o espraiamento das adesões e condições para a crítica teórica e política à concepção conservadora de profissão. 
O Código de Ética da profissão é a melhor expressão da vontade coletiva, nos termos gramscianos, e é um dos pilares, por ter em seu substrato a compreensão de que a emancipação humana não deve ser um projeto para o capitalismo, embora reconheça a necessária emancipação política de sujeitos viventes no capitalismo, até como forma de construção da liberdade possível. Também está no código, portanto, é compromisso profissional, a adoção de princípios filosóficos não irracionalistas, o que nos coloca no centro da nossa vontade. Na perspectiva ali defendida, a justiça social remete à defesa da socialização da riqueza apropriada privadamente, o que afirma a intenção da crítica ao capitalismo.

Do ponto de vista da atuação profissional na atual ordem, a profissão defende a existência e abrangência das políticas públicas. Este é o campo privilegiado do trabalho profissional e onde se faz urgente a luta em prol de um projeto político de superação das iniquidades e das opressões, como nos mostra a pandemia que estamos atravessando, recolocando a centralidade da proteção social como dever do Estado. A liberdade como valor central e fundamento da ética está posta na perspectiva da práxis humana, que seja acessível, se constitua realidade e não mero idealismo.

O chamado que estamos atendendo é o da resistência à despolitização da sociedade, à elitização da Universidade, à criminalização da juventude, sobretudo de mulheres, negros e população LGBTQIA+, ao desmonte de direitos sociais e da luta pela proteção à vida e a justiça social. A busca constante pela dignidade do trabalho profissional, contra os desmontes de direitos e de serviços. Nesta arena, toda forma de lutar vale a pena, parafraseando Fernando Pessoa.

\section{Referências}

BARROCO, Maria Lúcia Silva. Ética e Serviço Social: Fundamentos Ontológicos. São Paulo: Cortez, 2001.

. Não passarão. Ofensiva neoconservadora e Serviço Social. In; Revista

Serviço Social e Sociedade, n, 124. São Paulo: Cortez, 2015. Disponível em: <https://www.scielo.br/pdf/sssoc/n124/0101-6628-sssoc-124-0623.pdf.> Acesso em: 27 abr 2020.

BOTTOMORE, Tom. Fascismo. in: BOTTOMORE, Tom. (editor). Dicionário do pensamento marxista. Rio de Janeiro: Jorge Zahar Editor, 2001. 
CALIL, Gilberto. Gramsci e o fascismo. In: CISLAGHI, Juliana Fiuza; DEMIER, Felipe (orgs.). O neofascismo no poder (Ano I): Análises críticas sobre o governo Bolsonaro. Rio de Janeiro: Consequência, 2019. p. 47-67. CFESS. Código de Ética do/a Assistente Social e Lei 8.662/93. 10.ed.. Brasília: CFESS, 2012.

Sou Assistente Social e aqui estão as minhas bandeiras de luta!: conheça a pauta política do Serviço Social brasileiro construída coletivamente ao longo dos últimos anos pelo Conjunto CFESS-CRESS. Net, mar. 2020. Disponível em: < http://www.cfess.org.br/arquivos/Cartilha-BandeiradeLutas2019.pdf $>$. Acesso em 07 mar. 2020.

CHAUÍ, Marilena. Convite à Filosofia. São Paulo: Ática, 1997. CISLAGHI, Juliana Fiuza e DEMIER, Felipe. (orgs.) O neofascismo no poder (Ano I): Análises críticas sobre o governo Bolsonaro. Rio de Janeiro: Consequência, 2019.

COUTINHO, Carlos Nelson. Democracia e Socialismo. São Paulo: Cortez, 1992.

GRAMSCI, Antonio. Cadernos do Cárcere. v. 3. 7. ed. Rio de Janeiro: Civilização Brasileira, 2016.

GUERRA, Yolanda. A instrumentalidade do Serviço Social. 10. ed. São Paulo: Cortez, 2013.

HELLER, Agnes. O cotidiano e a história. Tradução de Carlos Nelson Coutinho e Leandro Konder. 4. ed. São Paulo: Paz e Terra, 1992.

IAMAMOTO, Marilda. Vilella. Serviço social em tempo de capital fetiche: capital financeiro, trabalho e questão social. 2. ed. São Paulo: Cortez, 2008.

LÖWY, Michel. A Teoria da Revolução no jovem Marx. São Paulo: Boitempo, 2012.

NETTO, José Paulo. Capitalismo Monopolista e Serviço Social. São Paulo: Cortez, 1992.

TABER, Myke e RIDELL, John. Introdução. In: ZETKIN, Clara. Como nasce e morre o fascismo. Tradução de Eli Moraes. São Paulo: Autonomia literária, 2019. p. 11-31.

TROTSKY, Leon. Como esmagar o fascismo. Tradução de Aldo Sauda e Mario Pedrosa. São Paulo: Autonomia literária, 2018. 
ZETKIN, Clara. Como nasce e morre o fascismo. Tradução de Eli Moraes. São Paulo: Autonomia literária, 2019. 
